ISBN 978-93-84468-86-6

2016 International Research Conference on Social Sciences, Humanities and Interdisciplinary Studies

(RCSSHIS-2016)

Pattaya (Thailand) Dec. 16-17, 2016

\title{
Factors of Work Performance Motivation of Chinese workers in Thailand
}

\author{
Dr. WatcharaYeesuntes, and Zhaoyu Fan \\ watchara.yee@kbu.ac.th \\ Post Graduate School of business administration \\ KasembunditUniversity,Bangkok
}

\begin{abstract}
The purpose of this study was to determine factors of work performance motivation of Chinese workers in Thailand. Sample were 385 Chinese workers who work in Thailand by using a check list and rating scale questionnaire. The statistics used for data analysis were percentage, mean, standard deviation, T-test, One-way Anova, and regression analysis.

Findings revealed that most of respondents were females, age between 21-25 years old, bachelor degree graduated, private company workers, monthly income between 15,000-20,000 baht, and 2 years of work experienced. Factors of work performance motivator were in high level which consisted of following aspects: job description, work recognition, work responsibility, career advancement, work completion, company administrative and policy, job security, work environment, relationship with supervisors, relationship with coworkers, and salary and compensation. Factors of personal difference, such as level of education, monthly income, and work experience effected work performance motivation at statistical significant 0.05 level, also factors of work performance motivation aspects, such as salary, compensation, job completion, job responsibility, relationship with coworkers, work environment, and modern work equipmentcorrelated to work performance at statistical significant 0.05 level.

Recommendations from this study were that administrative officers should adjust on salary and compensation,offer emergency funds, medical benefit, re-design work environment, appropriate necessary work equipment to ease workers on the operation.
\end{abstract}

Keywords: Factors, Performance

\section{Introduction}

Presently, international business development cooperation between China and Thailand has a respectable relationship. Therefore there are a number of Chinese businessmen who are doing business in the country. This creates a good opportunity to Chinese who are interested in working in Thailand. Accordingly, many Chinese have decided to come and work in Thailand.From the intense business competition nowadays, enterprises have to face higher risks with business problems and the environment rapidly changes due to economic, politic, social, and modern technology which continue to develop. Such an impact the organizations necessitymodify to different strategies, most of companies starts from internal factors to begin with which is easier to control the outcome of efficiency and effectiveness.

From the national economic and social development plan, issue number 11. (2555-2559) gives priority to the development of people and society simultaneously. People are at the center of development and bring in philosophy of "sufficiency economy" to build and develop the country (Office of the National Economics and Social Development Board. (2554: 19)). Therefore, whether organizations are Government or private agencies necessity give priority to people in the organization. To manage human resource, executive officers must have the knowledge, ability, then the technique to begin with, have good assertiveness toward employees, persuade employees to faithful and satisfy with their job in company, to make employees satisfy and concentrating on 
their work for maximum benefit to the corporation, it will rely on several elements, such as work performance motivation, If executives can influence employee to motivate in their job as a result, personnel are willing to work with full efforts to achieve the goals or objective of the organization.

Different profession, such as tourists guide persons, corporate workers, interpreters, and Chinese Language teachers for example, have difference work efficiency. Therefore, Chinese people who want to work in the country need to develop their own skills to work with efficiency. However, personal knowledge capability of employees alone will only be parted of the organization success, but to get whole benefit both organization and employees need to improve development relationship together in order to so called win-win for all.

\section{Literature Review}

\section{Two-factor theory and concepts of Frederick Herzberg's Two-Factor Theory}

Two-factor theory distinguishes between:

1. Motivators (e.g. challenging work, recognition for one's achievement, responsibility, opportunity to do something meaningful, involvement in decision making, sense of importance to an organization) that give positive satisfaction, arising from intrinsic conditions of the job itself, such as recognition, achievement, or personal growth, and

2. Hygiene factors (e.g. status, job security, salary, fringe benefits, work conditions, good pay, paid insurance, vacations) that do not give positive satisfaction or lead to higher motivation, though dissatisfaction results from their absence. The term "hygiene" is used in the sense that these are maintenance factors. These are extrinsic to the work itself, and include aspects such as company policies, supervisory practices, or wages/salary Herzberg often referred to hygiene factors as "KITA" factors, which is an acronym for "kick in the ass", the process of providing incentives or threat of punishment to make someone do something.

According to Herzberg, hygiene factors are what causes dissatisfaction among employees in a workplace. In order to remove dissatisfaction in a work environment, these hygiene factors must be eliminated. There are several ways that this can be done but some of the most important ways to decrease dissatisfaction would be to pay reasonable wages, ensure employees job security, and to create a positive culture in the workplace. Herzberg considered the following hygiene factors from highest to lowest importance: company policy, supervision, employee's relationship with their boss, work conditions, salary, and relationships with peers. Eliminating dissatisfaction is only one half of the task of the two factor theory. The other half would be to increase satisfaction in the workplace. This can be done by improving on motivating factors. Motivation factors are needed to motivate an employee to higher performance. Herzberg also further classified our actions and how and why we do them, for example, if you perform a work related action because you have to then that is classed as "movement", but if you perform a work related action because you want to then that is classed as "motivation". Herzberg thought it was important to eliminate job dissatisfaction before going onto creating conditions for job satisfaction because it would work against each other.

\section{The Purpose of the Study}

To study the factors of work performance motivation affects Chinese workers in Thailand. 


\section{Conceptual Framework of the Study}

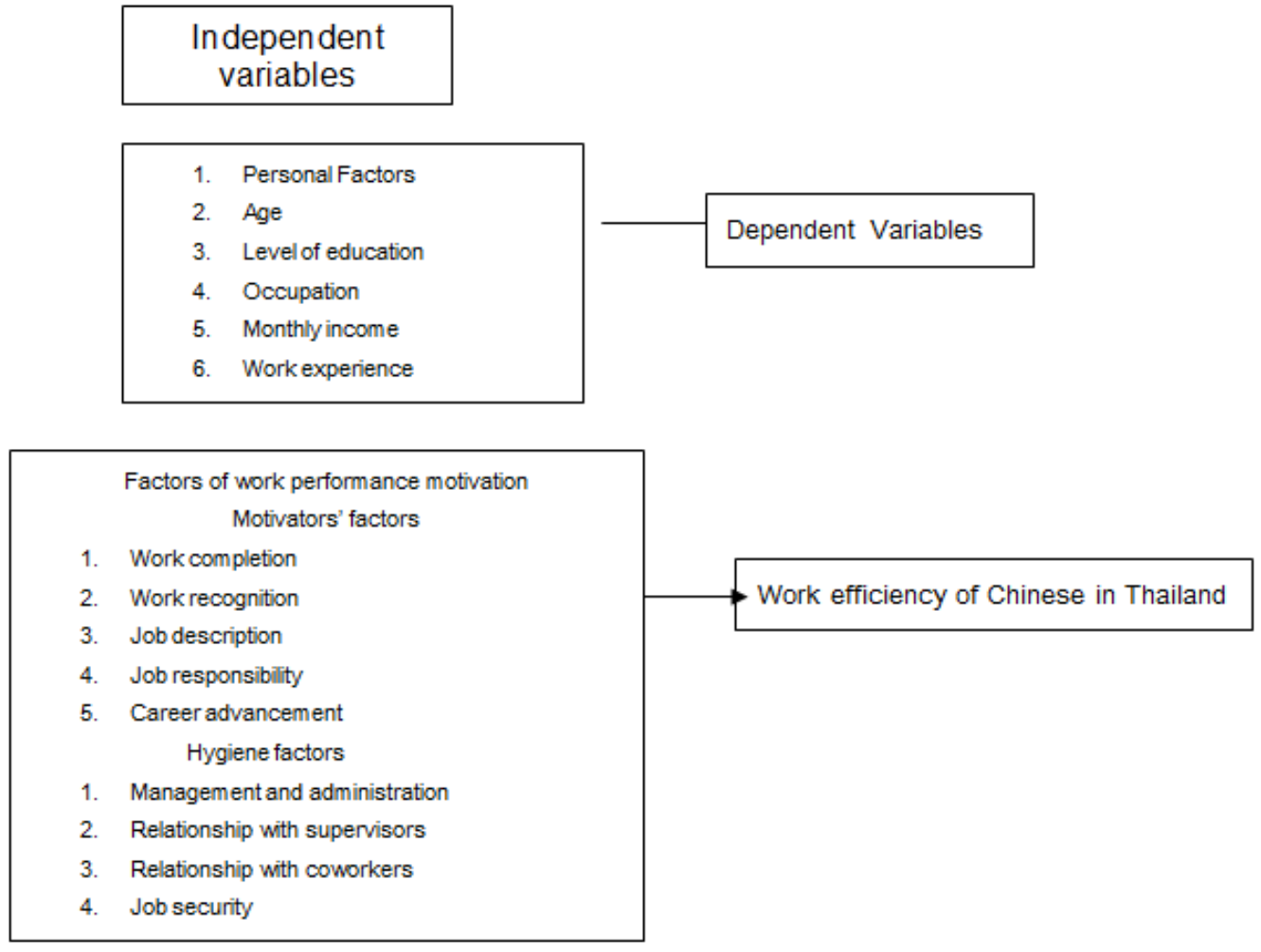

\section{Sample Selection}

Sample size for $\pm 5 \%, \pm 7 \%$ and $\pm 10 \%$ Precision Levels Where Confidence Level is $95 \%$ and $\mathrm{P}=.5$.

Assume there is a large population but that we do not know the variability in the proportion that will adopt the practice; therefore, assume $\mathrm{p}=.5$ (maximum variability). Furthermore, suppose we desire a 95\% confidence level and $\pm 5 \%$ precision. The resulting sample size is demonstrated in Equation

$$
n_{0}=\frac{Z^{2} p q}{e^{2}}=\frac{(1.96)^{2}(.5)(.5)}{(.05)^{2}}=385 \text { farmers }
$$

\section{Data Collection Procedure}

The questionnaires were distributed to sample of 385 Chinese people who work in Thailand. A total of 385 usable questionnaires were returned back to the researcher, yielding a 100 percent response rate and no missing data.

TABLE I comparison of the factors of personal difference, such as gender effect factors of work efficiency of Chinese who work in Thailand

\begin{tabular}{|c|c|c|c|c|c|c|}
\hline Gender & $\mathrm{N}$ & Mean & $\mathrm{t}$ & $\mathrm{df}$ & Sig. & testing \\
\hline Male & 153 & 3.641 & 1.372 & 0.383 & 0.469 & No different \\
\hline female & 232 & 3.487 & & & & \\
\hline
\end{tabular}

Hypothesis testing revealed that t-test with significance level at 0.05 which important of factors of personal difference, such as gender effecting work performance with significant level 0.469 which was greater than significance level 0.05 , meaning that tested accepted hypothesis $\mathrm{H} 0$, result was factors of personal difference, such as gender was not effect factors of work efficiency of Chinese who work in Thailand. 
TABLE II comparison of the factors of personal difference, such as age effect factors of work efficiency of Chinese who work in Thailand

\begin{tabular}{|c|c|c|c|c|c|c|}
\hline Work efficiency & SS & df & MS & F & Sig. & testing \\
\hline Between group & 4.551 & 3 & 1.517 & 1.919 & .126 & No different \\
\hline Within group & 301.153 & 381 & .790 & & & \\
\hline total & 305.704 & 384 & & & & \\
\hline
\end{tabular}

Hypothesis testing revealed that One-way Anova with significance level at 0.05 found that factors of personal difference, such as age effecting work performance with significant level 0.126 which was greater than significance level 0.05 , meaning that tested accepted hypothesis H0, result was that factors of personal difference, such as age was not effect factors of work efficiency of Chinese who work in Thailand.

TABLE III comparison of the factors of personal difference, such as level of education effect factors of work efficiency of Chinese who work in Thailand

\begin{tabular}{|c|c|c|c|c|c|c|}
\hline Work efficiency & SS & df & MS & F & Sig. & testing \\
\hline Between group & 5.625 & 2 & 2.812 & 3.580 & $.029^{*}$ & Different \\
\hline Within group & 300.079 & 382 & .786 & & & \\
\hline total & 305.704 & 384 & & & \\
\hline
\end{tabular}

*Significant level 0.05

Hypothesis testing revealed that One-way Anova with significance level at 0.05 found that factors of personal difference, such as level of education effecting work performance with significant level 0.029 which was less than significance level 0.05 , meaning that tested accepted hypothesis $\mathrm{H} 1$, result was that factors of personal difference, such as level of education effected factors of work efficiency of Chinese who work in Thailand.

TABLE IV comparison of the factors of personal difference, such as occupation effect factors of work efficiency of Chinese who work in Thailand

\begin{tabular}{|c|c|c|c|c|c|c|}
\hline Work efficiency & SS & df & MS & F & Sig. & testing \\
\hline Between group & 4.904 & 3 & 1.635 & 2.071 & .104 & No different \\
\hline Within group & 300.800 & 381 & .790 & & & \\
\hline total & 305.704 & 384 & & & & \\
\hline
\end{tabular}

Hypothesis testing revealed that One-way Anova with significance level at 0.05 found that factors of personal difference, such as occupation effecting work performance with significant level 0.104 which was greater than significance level 0.05 , meaning that tested accepted hypothesis H1, result was that factors of personal difference, such as occupation was not effect factors of work efficiency of Chinese who work in Thailand.

TABLE V comparison of the factors of personal difference, such as monthly income effect factors of work efficiency of Chinese who work in Thailand

\begin{tabular}{|c|c|c|c|c|c|c|}
\hline Work efficiency & SS & df & MS & F & Sig. & testing \\
\hline Between group & 17.883 & 3 & 5.961 & 7.891 & $.000^{*}$ & Different \\
\hline Within group & 287.821 & 381 & .755 & & & \\
\hline total & 305.704 & 384 & & & & \\
\hline
\end{tabular}

*Significant level 0.05

Hypothesis testing revealed that One-way Anova with significance level at 0.05 found that factors of personal difference, such as monthly income effecting work performance with significant level 0.00 which was less than significance level 0.05 , meaning that tested accepted hypothesis H1, result was that factors of personal difference, such as monthly income effected factors of work efficiency of Chinese who work in Thailand.

TABLE VI comparison of the factors of personal difference, such as work experienced effect factors of work efficiency of Chinese who work in Thailand

\begin{tabular}{|c|c|c|c|c|c|c|}
\hline Work efficiency & SS & df & MS & F & Sig. & testing \\
\hline Between group & 19.723 & 3 & 6.574 & 8.759 & $.000^{*}$ & Different \\
\hline Within group & 285.981 & 381 & .751 & & & \\
\hline total & 305.704 & 384 & & & & \\
\hline
\end{tabular}

*Significant level 0.05

Hypothesis testing revealed that One-way Anova with significance level at 0.05 found that factors of personal difference, such as work experienced effecting work performance with significant level 0.00 which was less than significance level 0.05, meaning that tested accepted hypothesis H1, result was that factors of personal 
difference, such as work experienced was not effect factors of work efficiency of Chinese who work in Thailand.

\section{Summary of Study Results}

Findings revealed that most of respondents were females, age between 21-25 years old, bachelor degree graduated, private company workers, monthly income between 15,000-20,000 baht, and 2 years of work experienced

\section{Suggestions for Future Research}

Should study on relationship of Chinese personnel who work in Thailand.

\section{References}

[1] GatesudaTontun. (2546). Variables associated with work performance motivation of registered Nurses at Samitivech Hospital , Sukhumvit, Bangkok, Thesis, Master of Education, Srinakarinviroj University publisher.

[2] GantayaPermphol. (2552). Factors of work performance motivation of personnel at Post officeCenter, Thesis, Master of Business Administration, Kasem Bundit University.

[3] KittipongSiriporn. (2551). Factors of work performance development motivation of operational Level employees: Case study, Automobile production factory, SamutPragarn Province, Sripatum University publisher.

[4] KanyanunPattarasornsiri. (2554). Factors of work performance efficiency of personnel atPatumwan Technology Institute, publisher.

[5] KhanjiraThongnum. (2547). Factors of work performance motivation of government teachers. The College of Dramatic Arts, Silapakorn Department, Master of Education, Srinakarinviroj University publisher.

[6] JaruwanKamolsilp. (2548). Employees work motivation of workers at Nava Nakorn Industrial Estate, Thesis, Master of Business Administration, ThurakitBundit University publisher.

[7] PanyaJanrod. (2548). Factors of work performance motivation of contract workers at RamkamheangUnivesity, Thesis, Master of Business Administration, Kasem Bundit University.

[8] PakornKocharoen. (2549). Factors of work development motivator of employees at KungthepPetchaburi Tour Co., Ltd., Petchaburi Province, Thesis, Master of Business Administration, Chiang Mai University publisher.

[9] Herzberg, Frederick; Mausner, Bernard; Snyderman, Barbara B. (1959). The Motivation to Work (2nd ed.). New York: John Wiley. ISBN 0471373893

[10] Hackman, J. Richard; Oldham, Greg R. (August 1976). "Motivation through the Design of Work: Test of a Theory". Organizational Behavior and Human Performance. 16 (2): 250-279. Doi: 10.1016/0030-5073(76)90016-7. OCLC 4925746330.

https://doi.org/10.1016/0030-5073(76)90016-7

[11]Herzberg, Frederick (January-February 1968). "One More Time: How Do You MotivateEmployees?" Harvard Business Review. 46 (1): 53-62. OCLC 219963337.

[12] "Herzberg's Motivation-Hygiene Theory (Two Factor Theory)". NetMBA.com. Retrieved December 9, 2014. 